\title{
PENGARUH PENERAPAN KOMPONEN PERAWATAN METODE KANGURU (PMK) TERHADAP LAMA PERAWATAN BAYI BERAT LAHIR RENDAH DI RUMAH SAKIT UMUM DAERAH PROF DR.W.Z.JOHANNES KUPANG
}

\author{
Intje Picauly ${ }^{1}$, Aquilina Akoit ${ }^{2}$, Paula Tibuludji ${ }^{3}$, Christin D. Nabuasa ${ }^{4}$ \\ ${ }^{1,4}$ Fakultas Kesehatan Masyarakat, Universitas Nusa Cendana \\ ${ }^{2}$ RSU Dr. W. Z. Johannes Kupang Dan STIKES MARANATHA Kupang \\ ${ }^{3}$ Doktor Philosofi Kesehatan Ibu dan Anak, IPMNH Kupang
}

Dinyatakan Layak Publikasi :
Kupang, 25 Januari 2019

\begin{abstract}
$\mathcal{A B S T R \mathcal { A K }}$
Riskesdas, 2013, menyatakan bahwa prevalensi BBLR tertinggi didapati di Provinsi Sulawesi Tengah sebesar 18,2\%, Nusa Tenggara Timur (NTT) sebesar 15,5\% dan Provinsi Papua (15,6\%), sedangkan prevalensi terendah di Provinsi Sumatera Utara sebesar 7,5\%, namun angka tersebut masih menjadi masalah kesehatan, karena menurut Depkes RI (2009), BBLR dikategorikan sebagai masalah kesehatan masyarakat apabila prevalensinya $\geq 5 \%$. RSUD Prof Dr W.Z Johannes Kupang tahun 2016 (Januari-Juni) kasus BBLR sebanyak 100 kasus dari total kelahiran 459 bayi baru lahir.

Penelitian ini bertujuan untuk mengetahui pengaruh penerapan komponen perawatan metode kanguru terhadap peningkatan status kesehatan BBLR. Jenis penelitian adalah observasional analitik dengan pendekatan cros sectional study. Teknik Pengambilan sampel dalam penelitian ini adalah total sampling dengan sampel 100 orang. Hasil analisis bivariat dengan uji chi square menunjukkan bahwa perawatan metode kanguru position berpengaruh terhadap peningkatan status kesehatan BBLR $(P R=2,79)$ dengan nilai $(\mathrm{Pv}=0,000$., $\mathrm{Pv}<0,05)$. Kanguru nutrition berpengaruh terhadap status kesehatan BBLR (PR = 2,47) dengan nilai $\left(\mathrm{Pv}=0,000 ., \mathrm{Pv}_{\mathrm{v}}<0,05\right)$. Kanguru support berpengaruh terhadap status kesehatan BBLR $(P R=2,72)$ dengan nilai $(P v=0,000$., $P v<0,05)$. Analisis multivariat dengan uji regresi logistik ganda menunjukkan bahwa kanguru nutrition paling berpeluang dalam peningkatan status kesehatan BBLR dengan nilai $\mathrm{p}=0,000$. Disarankan kepada ibu-ibu agar dapat berperan aktif dalam penerapan komponen PMK, karena tidak membutuhkan biaya dan bermanfaat dalam membangun hubungan kedekatan antara ibu dan bayi.
\end{abstract}

Kata kunci : Komponen Perawatan metode kanguru, status kesehatan, BBLR

\begin{abstract}
$\mathcal{A B S T \mathcal { T A C } T}$
Based on Indonesia Basic Health Research in 2013, the highest prevalence of $L B W$ was found in Central Sulawesi Province (18.2\%), East Nusa Tenggara (15.5\%) and Рариa (15.6\%) while the lowest prevalence was in North Sumatera Province $(7,5 \%)$. $L B W$ was considered as a public health problem because the prevalence was $\geq 5 \%$ (Ministry of Health, 2009). There were $100 \mathrm{LBW}$ cases recorded of 459 total births at The Regional General Hospital of Prof. Dr. W.Z Johannes in 2016 (January-June).

This study aimed to analyze the effect of Kangaroo Mother Care (KMC) on the improvement of $L B W$ health status. The research was observational analytic with cros-sectional design. A sample of 100 people was taken using total sampling technique. The result showed that KMC had an effect on increasing health status of $L B W(p=0,000 ; p<0,05)$. The study also indicated that Kangaroo nutrition $(p=0,000 ; p<0,05)$ and Kangaroo support $(p=0.000 ; p<0,05)$ were significantly correlated with the health status improvement of $L B W$. The result of multivariate analysis showed that Kangaroo nutrition was the major predictor variable in increasing health status of $L B W$ with $p=0,000$. Mothers need to take an active role in applying KMC as it was free of charge and it could help create a bond and attachment between mothers and babies.
\end{abstract}

Key words: Kangaroo Mother Care, Health Status, Low Birth Weight 


\section{PENDAHULUAN}

Bayi Berat Lahir Rendah (BBLR) adalah bayi dengan berat badan lahir kurang dari 2500 gram tanpa memandang masa gestasi (Depkes RI, 2009). BBLR hingga saat ini masih merupakan masalah kesehatan masyarakat dunia, karena sebagai penyebab kesakitan dan kematian pada masa neonatal. Angka prevalensi BBLR diperkirakan 15,5\% atau sekitar 20 juta bayi dari seluruh kelahiran di dunia dan 96,5\% berasal dari negara-negara berkembang dan angka kematian 35 kali lebih tinggi dibanding pada bayi dengan berat lahir lebih dari 2500 gram (Pantiawati, 2010).

BBLR termasuk salah satu faktor utama dalam peningkatan mortalitas dan morbiditas bayi dan anak serta memberikan dampak jangka panjang dalam kehidupannya (Mocthar R, 1998, dalam Cendekia, (2012 ). Menurut World Health Organization (WHO) dalam Maryunani (2012) mengatakan bahwa 17\% dari 25 juta persalinan pertahun didunia terjadi dinegara berkembang. Angka kejadian BBLR di Indonesia masih tinggi yaitu sebanyak $10,5 \%$, angka ini masih diatas angka rata-rata Thailand $(9,6 \%)$ dan Vietnam (5,2\%). Secara nasional berdasarkan analisa lanjut Survey Demografi dan Kesehatan Indonesia (SDKI,2012), angka kejadian BBLR masih sangat bervariasi antara satu daerah dengan daerah lain, yaitu berkisar antara 7,5\%-18,2\%. Hasil studi di 7 daerah multisenter diperoleh prevalensi BBLR dengan rentang antara 2,1\%-17,2\% (Proverawati dan Ismayanti, 2010). Angka ini lebih besar dari target yang ditetapkan pada sasaran program perbaikan gizi menuju Indonesia sehat 2010 yakni maksimal 7\% (SDKI, 2007 dalam Pantiawati, 2010).

Hasil Riset Kesehatan Dasar (Riskesdas, 2013), menyatakan bahwa prevalensi BBLR tertinggi masih didapati di Provinsi Sulawesi Tengah sebesar 18,2\%, Nusa Tenggara Timur (NTT) sebesar 15,5\% dan Provinsi Papua (15,6\%), sedangkan prevalensi terendah di Provinsi Sumatera Utara sebesar 7,5\%, namun angka tersebut masih menjadi masalah kesehatan, karena menurut Depkes RI (2009), BBLR dikategorikan sebagai masalah kesehatan masyarakat apabila prevalensinya $\geq 5 \%$. Data Dinas Kesehatan Provinsi Nusa Tenggara Timur tahun 2015, mengatakan bahwa jumlah bayi yang lahir hidup sebanyak 92.567 dan meninggal sebanyak 909 bayi dengan tiga penyebab kematian bayi baru lahir terbesar adalah BBLR yaitu sebanyak 298 bayi (32,8\%), Asfiksia sebesar 264 bayi (29,0\%), dan infeksi 72 bayi $(0,10 \%)$. Data rekam medik RSUD Prof. Dr. W. Z. Johannes Kupang tahun 2014 jumlah BBLR sebanyak 288 bayi dengan rincian 201 bayi hidup dan 27 bayi meninggal. Tahun 2015 terdapat 442 BBLR, dan tahun 2016 periode Januari- Juni 2016 terdapat 100 bayi dengan berat lahir rendah dari total bayi baru lahir sebanyak 459 bayi.

Tingginya angka kejadian BBLR ini disebabkan oleh kelahiran premature. Faktor penyebab kelahiran premature yaitu faktor maternal adalah penyakit yang dialami oleh ibu selama kehamilan, komplikasi persalinan dan infeksi maternal. Faktor fetal adalah kehamilan ganda, malformasi kongenital, faktor medical oleh 
karena ibu menderita penyakit seperti jantung, hipertensi, diabetes melitus (Desnawati, 2012). Jika komplikasi yang terjadi tidak ditangani dengan segera dan tepat maka akan mengakibatkan kematian (Proverawati, 2010).

Perawatan BBLR dengan inkubator masih mengalami banyak keterbatasan, terutama karena jumlahnya yang terbatas, memerlukan biaya yang tinggi, memiliki tenaga terampil, angka kejadian infeksi nosokomial cukup tinggi dan dinilai menghambat kontak dini ibu-bayi serta menghambat pemberian ASI. Oleh karena itu diperlukan suatu metode praktis sebagai alternative pengganti inkubator yang secara ekonomis cukup efisien dan efektif yaitu Perawatan Metode Kanguru (PMK), (Suradi, 2009 ; Silvia, et all, 2015).

PMK merupakan perawatan untuk bayi berat lahir rendah atau kelahiran premature dengan melakukan kontak langsung antara kulit bayi dengan kulit ibu atau skin-to-skin contact, dimana ibu menggunakan suhu tubuhnya untuk menghangatkan bayi (IDAI, 2010). Menurut Suradi (2010), dalam penerapan PMK harus memperhatikan komponen-komponennya antara lain Kangaroo Position (Posisi) yaitu meletakkan bayi di antara payudara ibunya dengan posisi tegak, dada bayi menempel ke dada ibu. Bayi dalam keadaan telanjang hanya mengenakan popok, kaos kaki dan topi sehingga terjadi kontak kulit bayi dengan kulit ibu secara kontinyu dan bayi memperoleh panas (sesuai suhu ibunya) melalui proses konduksi. Kangaroo Nutrition (Nutrisi) yaitu bayi berhadapan dengan ibu, perut bayi menempel pada perut ibu, telinga dan lengan berada pada satu garis dan ibu bertatap muka dengan bayinya, sehingga bayi dapat menetek dengan baik. Cara ini dapat meningkatkan pemberian ASI secara langsung bila bayi sudah siap mengisap maupun dengan pemberian ASI perah. Kangaroo Support (Dukungan) yaitu bentuk dukungan secara fisik maupun emosional, dari keluarga maupun tenaga kesehatan, sehingga ibu dapat melakukan metode ini dengan baik dan benar, karena dengan PMK diharapkan rasa cemas ibu berkurang dan tumbuh rasa percaya diri ibu. Upayaupaya tersebut dilakukan untuk menurunkan angka kematian BBLR, namun angka prevalensinya masih tetap $\geq 5 \%$ Depkes RI (2009).

\section{METODE PENELITIAN}

Jenis penelitian ini adalah penelitian observasional analitik dengan desain penelitian Cross Sectional study yaitu untuk menganalisis pengaruh antara variabel independent (bebas) yaitu penerapan komponen PMK : kanguru position, kanguru nutrition dan kanguru support dengan variable dependen (terikat) yaitu peningkatan status kesehatan bayi, dengan observasi atau pengumpulan data dalam waktu yang bersamaan. Tempat penelitian ini dilaksanakan di ruang NICU/NHCU RSUD Prof. Dr. W. Z. Johannes Kupang. Waktu pengumpulan data dilaksanakan selama 3 bulan terhitung bulan Januari-Maret 2017. Populasi, semua bayi yang lahir dengan berat lahir rendah yang dirawat di ruang perawatan NICU/NHCU RSUD Prof. Dr. W. Z. Johannes Kupang selama Periode Januari - Juni 2016 sebanyak 100 orang. 
Sampel, seluruh bayi yang baru lahir yang dirawat di ruang NICU/NHCU RSUD Prof. Dr. W. Z. Johannes Kupang selama Periode Januari - Maret 2017 yang terdiagnosa BBLR dan memenuhi ketentuan atau persyaratan sampel seperti :

1) Untuk Bayi :

a. Bayi dengan Berat lahir kurang dari 2.500 gram dengan penerapan Perawatan Metode Kanguru (PMK).

b. Bayi yang dirawat di ruang Perawatan Neonatal Intensif Care Unit/NICU, Nursig Home Care Unit/NHCU RSUD Prof. DR. W. Z. Johannes Kupang.

c. Bayi Berat Lahir Rendah (BBLR) yang masa perawatan lebih dari 3 hari.

d. Bayi Berat Lahir Rendah tanpa menggunakan oksigen.

2) Untuk Ibu Bayi Sampel :

a. Ibu yang sehat secara fisik dan mental.

b. Ibu mampu dan mau melakukan Perawatan Metode Kanguru.

c. Ibu yang tidak menderita penyakit berat dan dapat merawat bayinya.

Teknik Pengolahan, Analisis, pengumpulan data dilakukan dengan cara mengobservasi tindakan Perawatan Metode Kanguru. Alat yang digunakan adalah digital clinical thermometer (Thermo One), arloji/jam tangan dan timbangan bayi serta lembar observasi dimana hasil pengukuran suhu axilla selama5 menit, perhitungan frekuensi denyut jantung selama 1 menit, melakukan penimbangan berat badan bayi, yang kemudian akan ditulis dalam lembar observasi. Teknik observasi dilakukan oleh peneliti dan di bantu oleh kepala ruangan/ketua tim dan penanggung jawab shif.

Teknik Analisa Data, Analisis Univariat untuk melihat distribusi, frekuensi dan persentase dari masing-masing variable yang diteliti, Analisa Bivariat, untuk menguji ada tidaknya pengaruh antara variable independen dan variable dependen. Analisis statistik yang digunakan dalam penelitian ini adalah statistik uji chi-square dengan derajat kepercayaan 95\% ( $\mathrm{a}=0,05)$, untuk melihat besar resiko yang dilambangkan dengan nilai PR (Prevalance Rate) dan untuk mengetahui pengaruh antara masing-masing variabel bebas (penerapan komponen perawatan metode kanguru position, nutriotion dan kanguru support ) terhadap variable terikat (peningkatan status kesehatan bayi berat lahir rendah) dengan nilai $\mathrm{p}<0,05$. Analisa Multivariat, Analisa yang dilakukan terhadap lebih dari dua variabel yang bersangkutan (variable independent dan variabel dependent). Selanjutnya analisa dilakukan dengan uji Regresi Logistik Berganda untuk mengetahui pengaruh penerapan komponen PMK mana yang lebih erat hubungannya terhadap peningkatan status kesehatan BBLR.

\section{HASIL DAN PEMBAHASAN}

Bayi Berat Lahir Rendah (BBLR) adalah bayi dengan berat badan lahir kurang dari 2500 gram tanpa memandang masa gestasi (Depkes RI, 2009). BBLR hingga saat ini masih merupakan masalah kesehatan masyarakat dunia, karena sebagai penyebab 
kesakitan dan kematian pada masa neonatal dengan berbagai determinan. Pada Tabel 1. Terlihat karakteristik dari ibu responden.

Tabel 1. Profil Reponden berdasarkan faktor usia, tingkat pendidikan dan status pekerjaan ibu responden di RSUD Prof. Dr. W. Z. Johannes Kupang

\begin{tabular}{|c|c|c|}
\hline Karakteristik Responden & Jumlah (n) & Persentase $(\%)$ \\
\hline \multicolumn{3}{|l|}{ Umur : } \\
\hline 1. 18-25 Tahun & 20 & 20,0 \\
\hline 2. 26-35 Tahun & 68 & 68,0 \\
\hline 3. 36-45 Tahun & 12 & 12,0 \\
\hline \multicolumn{3}{|l|}{ Tingkat Pendidikan : } \\
\hline 1. Rendah (Tamat SD) & 32 & 32,0 \\
\hline 2. Menengah (Tamat SMP-SMU) & 61 & 61,0 \\
\hline 3. Tinggi (Tamat D3-PT) & 7 & 7,0 \\
\hline \multicolumn{3}{|l|}{ Pekerjaan: } \\
\hline 1. Rendah (aktifitas fisik < 5 jam/hari) & 35 & 35,0 \\
\hline $\begin{array}{l}\text { 2. Menengah (aktifitas fisik } 5-10 \\
\text { jam/hari) }\end{array}$ & 62 & 62,0 \\
\hline 3. Tinggi (aktifitas fisik $\geq 10$ jam/hari) & 3 & 3,0 \\
\hline Total & 100 & 100,0 \\
\hline
\end{tabular}

Tabel 1. menunjukkan bahwa sebagian besar (68\%) responden berada pada interval usia 26-35 tahun dengan tingkat pendidikan sebagian besar $(61 \%)$ berada pada tingkat pendidikan menengah. Jenis pekerjaan responden sebagian besar $(62 \%)$ ada pada jenis pekerjaan sedang/menengah.

Tabel 2. Distribusi Reponden berdasarkan Variabel Penerapan Komponen PMK di RSUD Prof. Dr. W. Z. Johannes Kupang

\begin{tabular}{|c|c|c|}
\hline Variabel Penelitian & Jumlah (n) & Persentase $(\%)$ \\
\hline \multicolumn{3}{|l|}{ Kanguru Position : } \\
\hline 1. Tidak & 19 & 19,0 \\
\hline 2. $\mathrm{Ya}$ & 81 & 81,0 \\
\hline \multicolumn{3}{|l|}{ Kanguru Nutrition : } \\
\hline 1. Tidak & 21 & 21,0 \\
\hline 2. $\mathrm{Ya}$ & 79 & 79,0 \\
\hline \multicolumn{3}{|l|}{ Kanguru Support } \\
\hline 1. Tidak & 21 & 21,0 \\
\hline 2. $\mathrm{Ya}$ & 79 & 79,0 \\
\hline \multicolumn{3}{|l|}{ Lama Perawatan Bayi : } \\
\hline 1. Lama (> 30 hari perawatan) & 48 & 48,0 \\
\hline 2. Tidak Lama ( $\leq 30$ hari Perawatan) & 52 & 52,0 \\
\hline Total & 100 & 100,0 \\
\hline
\end{tabular}

Tabel 2. menunjukkkan bahwa sebagian besar (> 50\%) responden menerapkan komponen PMK yaitu kanguru position dengan baik. Dimana, penerapan metode kanguru nutrition dan support masing-masing 79\%; sedangkan penerapan kanguru position sebesar $81 \%$. Walaupun demikian, masih terdapat $48 \%$ bayi yang dilahirkan dengan kondisi BBLR harus dirawat lebih dari 30 hari perawatan di ruang NICU. 


\section{A. Pengaruh Penerapan Metode Kanguru Position dengan Lama Perawatan Bayi BBLR di RSUD Prof. Dr. W. Z. Johannes Kupang}

Kangaroo Mother Care (KMC) atau perawatan metode kanguru (PMK) merupakan perawatan untuk bayi berat lahir rendah atau lahir prematur dengan melakukan kontak langsung antara kulit bayi dengan kulit ibu atau skin-to-skin contact, dimana ibu menggunakan suhu tubuhnya untuk menhangatkan bayi. Hal yang harus diperhatikan dalam melakukan metode kanguru adalah posisi bayi. Perawatan metode ini harus dilakukan secara bertahap dan terus menerus. Semakin lama durasi melakukan metode ini semakin baik bagi bayi. Pada Tabel 3 terlihat kondisi ibu sampel melakukan metode PMK dengan cara mengatur posisi bayi. Tabel 3. menunjukkan bahwa lebih dari setengah responden $(64,2 \%)$ yang melaksanakan metode kanguru position dengan baik cenderung mempunyai status kesehatan yang baik dibandingkan dengan responden yang tidak melaksanakan metode kanguru position mempunyai status kesehatan sebanyak 100\%.

Tabel 3. Pengaruh Penerapan Metode Kanguru Position dengan Lama Perawatan Bayi BBLR di RSUD Prof. Dr. W. Z. Johannes Kupang

\begin{tabular}{|c|c|c|c|c|c|c|c|c|}
\hline \multirow{3}{*}{ No. } & \multirow{3}{*}{$\begin{array}{l}\text { Kanguru } \\
\text { Position }\end{array}$} & \multicolumn{4}{|c|}{ Lama Perawatan } & \multirow{2}{*}{\multicolumn{2}{|c|}{ Jumlah }} & \multirow{2}{*}{$\begin{array}{c}\text { Hasil } \\
\text { Analisis }\end{array}$} \\
\hline & & \multicolumn{2}{|c|}{ Lama } & \multicolumn{2}{|c|}{ Tidak Lama } & & & \\
\hline & & $\mathrm{n}$ & $\%$ & $\mathrm{n}$ & $\%$ & $\mathrm{n}$ & $\%$ & \multirow{3}{*}{$\begin{array}{c}\text { Pvalue }=0,000 \\
P R=2,79\end{array}$} \\
\hline 1. & Tidak & 19 & 100,0 & 0 & 0 & 19 & 100,0 & \\
\hline 2. & $\mathrm{Ya}$ & 29 & 35,8 & 52 & 64,2 & 81 & 100,0 & \\
\hline
\end{tabular}

Hasil uji statistik (prevalence rate) menunjukkan bahwa penerapan metode kanguru position merupakan faktor risiko terhadap peningkatan status kesehatan bayi berat lahir rendah karena memiliki nilai prevalence rate $>1$ yaitu sebesar 2,79. Hasil analisis menunjukkan bahwa indikator kanguru position dapat berpengaruh $\left(\mathrm{P}_{\text {value }}=0,000 ; \mathrm{P}_{\text {value }}<0,05\right)$ terhadap faktor lama perawatan Bayi Berat Lahir Rendah (BBLR).

Kanguru position merupakan salah satu komponen PMK dimana posisi bayi diletakkan diantara payudara ibu, dada bayi menempel ke dada ibu. Posisi bayi diamankan dengan kain panjang atau pengikat lainnya, dengan kepala bayi dipalingkan ke salah satu sisi dengan posisi sedikit tengadah (ekstensi). Ujung pengikat berada tepat dibawah kuping bayi. Posisi ini bertujuan untuk menjaga saluran napas tetap terbuka dan memberi peluang agar terjadi kontak mata antara ibu dan bayi. Pangkal paha harus dalam posisi fleksi dan melebar seperti dalam posisi kodok, tangan harus dalam posisi fleksi. Pastikan ikatan kain agar kuat sehingga bayi tidak tergelincir. Perut bayi jangan sampai tertekan dan posisi berada di sekitar epigasterium. Dengan cara ini bayi dapat terangsang dengan pernapasan perut dari ibunya. Kontak kulit bayi dan kulit ibu sangat mempengaruhi suhu tubuh bayi yang mana secara konstan dengan mekanisme umpan balik yang diatur oleh pusat pengatur suhu di hipotalamus otak akan membantu menghasilkan panas secara mandiri dan tidak tergantung pada suhu lingkungan. 
Maguire, et al. (2008) mengatakan bahwa BBLR belum memiliki kemampuan untuk meregulasi setiap stimulus sehingga dibutuhkan perawatan alternative dibanding perawatan intensif karena perawatan intensif membutuhkan banyak tindakan dimana menurut Darlow (1984) dalam Westrup et al. (2000) menyatakan bahwa bayi yang mendapat penanganan atau handling dalam sehari sebanyak 200 kali, stimulus tersebut membuat bayi stress dan mengalami hipoksia, gangguan tidur dan istirahat akibat, keadaan ini memberi dampak buruk terhadap perkembangan otak bayi. Menurut Bobak, Lowdermilk dan Jansen, 2005, menyatakan bahwa BBLR memiliki system organ yang belum matur sehingga akan mengalami hambatan untuk berinteraksi yang adaptif dengan lingkungan. Untuk itu dibutuhkan metode alternative yaitu PMK dimana ibu mendekap bayinya sehingga mengurangi stimulus yang berlebihan.

Dekapan ibu dengan metode kanguru position, menempatkan bayi pada posisi tegak, di antara payudara ibu, bayi dibiarkan telanjang hanya menggunakan popok, kaos kaki dan topi sehingga terjadi "kontak kulit bayi ke ibu" (skin-to-skin contact). Kontak kulit sebaiknya dimulai secara bertahap dari perawatan konvensional ke PMK dan hindari kontak yang berlangsung kurang dari 60 menit karena pergantian yang sering akan membuat bayi stress. Lama kontak kulit ditingkatkan secara bertahap sampai dilakukan terus menerus dan ditunda hanya untuk mengganti popok atau mandi. Dengan demikian dapat meningkatkan produksi panas dua kali lipat dari metabolisme tubuh, frekuensi denyut jantung bayi lebih stabil, pengaturan perilaku bayi lebih baik yaitu mengurangi frekuensi menangis bayi, dengan demikian penggunaan kalori lebih sedikit sehingga kenaikan berat badan lebih baik, waktu tidur dan istirahat lebih lama, hubungan lekat bayi-ibu lebih baik, serta berkurangnya kejadian infeksi (Suradi, R, 2010). Kanguru position dapat dilakukan oleh anggota keluarga seperti ayah atau suami, nenek, teman dekat yang bersedia untuk melakukan kontak kulit langsung dengan bayi dalam posisi kanguru.

Penelitian ini sejalan dengan penelitian yang dilakukan Andi Fatmasari (2016) yang menyatakan ada pengaruh yang signifikan antara penerapan metode kanguru position terhadap peningkatan status kesehatan bayi berat lahir rendah (BBLR) dengan nilai $(\mathrm{p}=0,000)$. Hasil penelitian ini juga sejalan dengan penelitian yang dilakukan oleh Sri Wahyuni (2015) dengan nilai $(\mathrm{p}=0,001)$ yang menyatakan bahwa penerapan metode kanguru position sangat berpengaruh terhadap peningkatan status kesehatan bayi berat lahir (BBLR) yang dialami. Seberapa besar status sehatnya bayi sangat dipengaruhi dari penerapan komponen metode kanguru yang di lakukan oleh ibunya.

\section{B. Pengaruh Penerapan Metode Kanguru Nutrition terhadap Lama Perawatan Bayi Berat Lahir Rendah di RSUD Prof. Dr. W. Z. Johannes Kupang}

Asupan gizi merupakan salah satu syarat penting dalam menjaga kesehatan tubuh, baik untuk usia pertumbuhan mulai dari janin hingga usia dewasa. Asupan gizi dibutuhkan terutama untuk proses pertumbuhan dan perkembangan anak sampai 
pada usia delapan belas tahun. Dalam kejadian, BBLR sangat dipentingkan asupan gizi bagi bayi yang baru dilahirkan lewat ibu yang menyusui. Oleh karena itu, Penerapan Metode Kanguru Nutrition terhadap status kesehatan bayi berat lahir rendah sangat penting. Hasil analisis pengaruh penerapan metode kanguru nutrition terhadap status kesehatan bayi berat lahir rendah dapat dilihat pada Tabel 4 .

Tabel 4. Pengaruh Penerapan Metode Kanguru Nutrition terhadap Lama Perawatan Bayi Berat Lahir Rendah di RSUD Prof. Dr. W. Z. Johannes Kupang

\begin{tabular}{ccccccccc}
\hline & & \multicolumn{4}{c}{ Lama Perawatan } & \multicolumn{2}{c}{ Jumlah } & \\
\cline { 3 - 7 } No & Kanguru & \multicolumn{2}{c}{ Lama } & \multicolumn{2}{c}{ Tidak Lama } & & \\
\cline { 3 - 7 } & Nutrition & $\mathrm{n}$ & $\%$ & $\mathrm{n}$ & $\%$ & $\mathrm{n}$ & $\%$ & \\
\hline 1. & Kurang Baik & 19 & 90,5 & 2 & 9,5 & 21 & 100,0 & $\mathrm{P}_{\text {value }}=0,000$ \\
2. & Baik & 29 & 36,7 & 50 & 63,3 & 79 & 100,0 & PR $=2,47$ \\
\hline
\end{tabular}

Tabel 4. menunjukkan bahwa sebagian besar responden (63,3\%) melaksanakan kanguru nutrition dengan baik mempunyai lama perawatan BBLR relatif lebih pendek dibanding dengan responden yang tidak melakukan metode kanguru. Hasil uji statistik (prevalence rate) menunjukkan bahwa penerapan metode kanguru nutrition merupakan faktor yang berisiko terhadap peningkatan status kesehatan bayi berat lahir rendah karena memiliki nilai prevalence rate $>1$ yaitu sebesar 2,47. Hasil analisis menunjukkan bahwa indikator kanguru nutrition berpengaruh $\left(\mathrm{P}_{\text {value }}=0,000 ; \mathrm{P}_{\text {value }}<0,05\right)$ terhadap lama perawatan kesehatan BBLR, artinya responden yang tidak melakukan metode kanguru position dengan baik memiliki resiko sebesar 2,79 kali untuk mempunyai lama perawatan yang lebih lama dibandingkan dengan responden yang melaksanakan metode kanguru nutrition kurang baik.

Nutrisi terbaik untuk BBLR adalah ASI karena mengandung laktosa yang merupakan jenis karbohidrat utama. Laktosa akan diubah menjadi glukosa dan galaktosa yang berperan dalam perkembangan system syaraf. Nutrisi ini membantu penyerapan kalsium dan magnesium dimasa pertumbuhan bayi. Lemak merupakan zat gizi terbesar kedua yang terkandung di ASI dan menjadi sumber energy utama. Lemak berperan dalam pengaturan suhu tubuh bayi. Pada bayi dengan berat lahir rendah diketahui bahwa lemak subcutan yang sangat tipis akibat belum maturnya system organ sehingga terjadi hambatan dalam melakukan interaksi yang adaptif (Bobak, Loedermilk dan Jansen, 2005). Kanguru nutrition merupakan suatu proses yang sangat ideal dalam proses menyusu karena bayi dalam keadaan rileks, beristirahat dengan posisi yang menyenangkan mirip dengan posisi dalam rahim. Dengan demikian Asupan nutrisi dapat meningkat (frekuensi menyusu lebih sering), meningkatkan produksi ASI, mengurangi kegelisahan/frekuensi menangis bayi, bayi tidur dan istirahat lebih lama. Keadaan demikian penggunaan kalori lebih sedikit sehingga kalori yang ada digunakan untuk menaikan berat badan (IDAI, 2010).

Penelitian ini sejalan juga dengan penelitian yang dilakukan Dewi Kurnia Ageng (2011) dan Armi (2015) yang menyatakan ada pengaruh yang signifikan antara penerapan metode kanguru nutrition terhadap peningkatan status kesehatan bayi berat badan lahir rendah (BBLR) dengan nilai $(p=0,024)$ dan nilai $(p=0,003)$. 
Kangaroo nutrition (nutrisi) merupakan salah satu manfaat PMK, yaitu meningkatkan pemberian ASI secara langsung bila bayi sudah siap mengisap maupun dengan pemberian ASI perah. Manfaat PMK salah satunya adalah memudahkan bayi dalam memenuhi kebutuhan nutrisi (ASI). ASI dapat memenuhi semua kebutuhan dasar bayi untuk tumbuh dan berkembang, baik kebutuhan fisisbiomedis (Asuh), kebutuhan kasih sayang/emosi (Asih) dan kebutuhan akan stimulus (Asah). Orang tua memegang peran untuk menciptakan lingkungan yang mendukung stimulasi yang diperlukan untuk perkembangan kognitif dan pemenuhan nutrisi yang adekuat. ASI yang adekuat dapat meningkatkan berat badan bayi sekurangkurangnya 20-40 gr/hari (IDAI, 2010). Hal ini sejalan juga dengan penelitian yang dilakukan Subedi (2014) menyatakan bahwa BBLR yang menjalani PMK menunjukkan kenaikkan berat badan sebesar 30 gram/hari, sedangkan Gupta (2014) dalam penelitiannya menyatakan bahwa kenaikan berat badan pada BBLR yang melakukan PMK hampir mirip yaitu mencapai 29 gram/hari.

\section{Pengaruh Penerapan Metode Kanguru Support terhadap Lama Perawatan Bayi dengan Status Bayi Berat Lahir Rendah}

Kangaroo support (dukungan) merupakan salah satu bentuk dukungan emosional dan fisik dari tenaga kesehatan dan keluarga untuk melakukan PMK. Dukungan emosional seperti memberikan informasi tentang manfaat PMK, memberikan pujian atas pelaksanaan perawatan metode kanguru. Hal ini akan membantu ibu yang mengalami keraguan untuk memenuhi kebutuhan bayi. Dukungan fisik sangat penting agar proses PMK dapat berjalan baik karena selama PMK akan sangat menyita waktu ibu. Metode kanguru support ini tidak hanya dilakukan oleh para ibu tetapi bisa dilakukan oleh orang terdekat seperti ayah, opa, nenek atau anggota keluarga yang bersedia untuk melakukan PMK agar dapat membantu meningkatkan status kesehatan BBLR, selain itu dapat menjalin hubungan bathin antara bayi dan ibu (IDAI, 2010).

Tabel 5. Pengaruh Penerapan Metode Kanguru Support terhadap Lama Perawatan Bayi Berat Lahir Rendah di RSUD Prof. Dr. W. Z. Johannes Kupang

\begin{tabular}{|c|c|c|c|c|c|c|c|c|}
\hline \multirow{3}{*}{ No } & \multirow{3}{*}{$\begin{array}{c}\text { Kanguru } \\
\text { Support }\end{array}$} & \multicolumn{4}{|c|}{ Lama Perawatan } & \multirow{2}{*}{\multicolumn{2}{|c|}{ Jumlah }} & \multirow{3}{*}{ Hasil Analisis } \\
\hline & & \multicolumn{2}{|c|}{ Lama } & \multicolumn{2}{|c|}{ Tidak lama } & & & \\
\hline & & $\mathrm{n}$ & $\%$ & $\mathrm{n}$ & $\%$ & $\mathrm{n}$ & $\%$ & \\
\hline 1. & Kurang Baik & 19 & 90,5 & 2 & 9,5 & 21 & 100,0 & $\mathrm{P}_{\text {value }}=0,000$ \\
\hline 2. & Baik & 29 & 36,7 & 50 & 63,3 & 79 & 100,0 & $\mathrm{PR}=2,72$ \\
\hline
\end{tabular}

Tabel 5. menunjukkan bahwa responden sebanyak 63,3\% melaksanakan metode kanguru support dengan baik mempunyai lama perawatan di ruang NICU RSUD Kupang relatif lebih singkat dibandingkan dengan responden yang tidak melaksanakan metode kanguru support. Hasil uji statistik (prevalence rate) menunjukkan bahwa penerapan metode kanguru support merupakan faktor yang dapat berisiko terhadap peningkatan status kesehatan bayi berat lahir rendah karena memiliki nilai prevalence rate $>1$ yaitu sebesar 2,72 . Hasil analisis menunjukkan 
bahwa indikator kanguru support berpengaruh $\left(\mathrm{P}_{\text {value }}=0,000 ; \mathrm{P}_{\text {value }}<0,05\right)$ terhadap status kesehatan BBLR. Penelitian ini sejalan dengan penelitian yang dilakukan Andi Fatmasari (2016) dan Armi (2015) yang menyatakan ada pengaruh yang signifikan antara penerapan metode kanguru support terhadap peningkatan status kesehatan bayi berat badan lahir rendah $(\mathrm{BBLR})$ dengan nilai $(\mathrm{p}=0,032)$ dan nilai $(\mathrm{p}=0,022)$.

Kanguru support merupakan bentuk dukungan secara fisik maupun emosional, dari tenaga kesehatan maupun keluarganya, sehingga ibu dapat melakukan metode ini untuk bayinya dengan baik dan benar karena dengan metode kanguru, diharapkan rasa cemas ibu akan berkurang dan tumbuh rasa percaya diri ibu. Metode ini merupakan salah satu metode yang sangat membantu tetapi memerlukan partisipasi aktif dari orang tua bayi dalam memberikan dukungan sehingga penerapan PMK dapat berjalan baik.

Hubungan emosional ibu dengan bayi dimulai sejak kehamilan sehingga ikatan emosional yang disebut attachment atau bonding ini merupakan suatu proses hubungan bayi dengan orangtuanya. Kebutuhan bayi terhadap orangtua bersifat absolut tetapi kebutuhan orang tua terhadap bayi bersifat relative karena bayi dengan kontak yang dini dengan ibunya lebih sedikit menangis, lebih sering tersenyum dan lebih banyak menyusu dari pada yang kontak dengan ibunya terlambat atau tidak adekuat (PERINASIA, 2003) Kanguru support ini tidak hanya dilakukan oleh para ibu tetapi bisa dilakukan oleh ayah, opa, nenek atau anggota keluarga yang bersedia untuk memberi dukungan dalam melakukan PMK. Dengan penerapan kanguru support bayi lebih sering kontak dengan ibu sehingga dapat menjalin hubungan bathin antara bayi dan ibu (IDAI, 2010).

Penerapan komponen PMK dapat dilakukan pada semua fasilitas pelayanan kesehatan termasuk masyarakat terutama wanita di pedesaan untuk menerima PMK dalam merawat BBLR secara mudah dan murah, dengan berbagai cara, adat kebiasaan untuk menolong bayi yang baru lahir. Kebiasaan yang dilakukan perlu studi serupa untuk mengenal istilah lokal dan kebiasaan setiap daerah agar dapat memudahkan dalam melakukan sosialisai perawatan metode kanguru dikemudian hari.

Upaya yang dilakukan masyarakat pedesaan dengan adat kebiasaan masingmasing semata adalah untuk meningkatkan status kesehatan bayi baru lahir seperti masyarakat pedesaan di Niki-Niki di kabupaten TTS dengan praktek "sei" masyarakat beranggapan bahwa, api dan asap dapat berpengaruh terhadap kesehatan. Tetapi jika dikaitkan dengan bayi yang lahir maka panas api dalam praktek "sei" dapat mencegah hipotermia, tetapi tidak memperhatikan efek dari asap api selama pemanggangan/pengasapan. Asap api akan terus berkutat didalam rumah karena rumah yang digunakan untuk praktek "sei" tidak memiliki ventilasi sebagai sirkulasi udara sehingga asap akan terus dihirup selama praktek "sei" (31-40 hari). Walaupun sangat sedikit yang menyatakan bahwa api dan asap dapat membahayakan pernapasan bayi baru lahir (Sudarmono, 2002). Tetapi Fadjar (2015), menyatakan 
bahwa asap api sangat berbahaya dan sama besar bahayanya dengan menyalakan seribu batang rokok. Asap api sangat berpotensi menjadi salah satu faktor pemicu yang membahayakan saluran pernapasan bayi baru lahir karena banyak mengandung partikel-partikel kecil dan gas-gas berbahaya dan yang paling tinggi adalah karbon monodioksida (CO), nitrogen dioksida (NO2) dan sulfur dioksida (SO2). Untuk itu perlu mensosialisasikan kebiasaan -kebiasaan yang baik, murah dan mudah untuk dilakukan yaitu dengan perawatan metode kanguru. Selain kebiasaan ada juga unsur sosial budaya khususnya yang berkaitan dengan praktek perawatan serta pemberian minuman pada bayi baru lahir. Untuk itu perlu mengidentifikasi unsur sosial budaya sebagai faktor penunjang atau penghambat agar dapat dimanfaatkan dalam upaya lebih memasyarakatkan PMK bagi mereka yang memerlukannya.

\section{PENUTUP}

Berdasarkan hasil penelitian tentang pengaruh penerapan komponen perawatan metode kanguru terhadap lama perawatan bayi berat lahir rendah di RSUD Prof. Dr. W. Z. Johannes Kupang, maka dapat disimpulkan bahwa: penerapan komponen perawatan metode kanguru position, kanguru nutrition dan kanguru support berpengaruh nyata terhadap lama perawatan bayi dan peningkatan status kesehatan BBLR. Namun, penerapan komponen PMK yaitu metode kanguru nutrition lebih dominan berpengaruh dibanding dua metode PMK lainnya dalam peningkatan status kesehatan bayi BBLR.

Berdasarkan simpulan di atas, disarankan kepada pihak RSUD Prof. Dr. W. Z. Johannes Kupang bahwa : 1). Ruang PMK dan ruang menyusui agar dipisah untuk menjaga privacy pasien sehingga pelaksanaan komponen kanguru support dapat mengikut sertakan suami atau ayah dari bayi; 2). Penerapan PMK tidak terbatas hanya pada PMK intermiten tetapi dilanjutkan dengan PMK kontinyu; 3). PMK perlu dilanjutkan di rumah ketika ibu dan bayi pulang, dengan membuat surat kontrol atau balasan rujukan ke fasilitas pelayanan dasar dengan membuat catatan pada buku KIA atau sejenisnya tentang status kesehatan bayi tersebut

\section{DAFTAR PUSTAKA}

Ahmad, N et all. 2010 Sistem Pengukuran Detak Jantung Manusia. Graha Ilmu : Yogyakarta

Bobak, 2005 Buku Ajar Keperawatan Maternitas. ECG: Jakarta

Desmawati. 2011. Intervensi Keperawatan Maternitas Pada Asuhan Keperawatan maternal. Trans Info Medika : Jakarta

Djelantik, I.G.G. at all. 2003. Perawatan Metode Kanguru. Perinasia : Jakarta

Departemen Kesehatan RI. 2009. Buku Panduan Pelatihan Manajemen Bayi Berat Badan Lahir Rendah untuk Bidan dan Perawat. Departeman Kesehatan : Jakarta 
Dinas Kesehatan Provinsi NTT. 2015. Laporan F1-F8. Dinas Kesehatan Provinsi NTT : Kupang

Ikatan Dokter Anak Indonesia, 2010. Perawatan Metode Kanguru. Nuha Medika: Jakarta

Kementrian Kesehatan RI. 2013. Buku Saku Pelayanan Kesehatan Neonatal Esensial. Penerbitan Badan Litbangkes : Jakarta

Lubis, 2003. Status Gizi Ibu Hamil Serta Pengaruh Terhadap Bayi Yang Di Lahirkan. Hipokrates: Jakarta

Maryunani, 2013. Asuhan Kegawatdaruratan Maternal Dan Neonatal. Trans Info Media : Jakarta

Mitayani, 2010. Mengenal Bayi Berat Lahir Rendah dan Penatalaksanaannya :

Baduose Media : Bandung.

Notoatmodjo, S. 2010. Metodologi Penelitian Kesehatan. PT. Rineka Cipta : Jakarta.

Pantiawati, I. 2010. Bayi dengan BBLR. Nuha Medika : Yogyakarta

Proverawati, A dan Ismawati, C.I. 2010. Berat Badan Lahir Rendah. Nuha Medika : Yogyakarta

Priya J.J. 2004. Kangaroo Care for Low Birth Weight Babies. Nursing Journal of India (95) 9: 209-212.http://proquest.umi.com (diunduh 8 Agustus 2016).

Suradi, R. at all. 2008. Perawatan BBLR dengan Metode Kanguru. Depkes RI : Jakarta

Survei Demografi dan Kesehatan Indonesia. 2012. Jakarta : BPS, BKKBN, Kemenkes, ICF International.

Silvia, dkk. 2015. Pengaruh Perawatan Metode Kanguru Terhadap Perubahan Berat Badan Bayi Lahir Rendah. Journal Iptek Terapan Volume 9 No.1 : Jakarta

Suradi, R dan Yanuarso, P. B. 2009. Metode Kanguru Sebagai Pengganti Inkubator Untuk Bayi Berat Lahir Rendah. Sari Pediatri Volume 2 No.1 : Jakarta

The Lancet. 2005. The Millenium Project : A Plan for Meeting The Millenium Development Goals (365) : 547-553. www.the lancet.com (Diunduh 8 Agustus 2008).

World Health Organization. 2003. Kangaroo Mother Care A Practical Guide. Geneva : RHR 